\title{
Examination the Digital Competence of Teacher Candidates in Terms of Different Variables
}

\author{
Agâh Tuğrul KORUCU *, Ahmet YÜCEL, Mustafa M. GÜNDOĞDU, \\ Tarık GENÇTÜRK \\ Necmettin Erbakan University, Konya, Turkey
}

\begin{abstract}
It has been essential to make use of technology in education as a result of the improvements in information and communication technology in the 21 st century. Teachers, who are the organizers and the developers of learning environments, need to have a high level of consciousness with regard to digital competence. Thus, students can acquire digital competence only if teachers do it first. The aim of this study is to analyse the digital competence of teacher candidates in terms of different variables. The study group consisted of 200 teacher candidates who study at different departments of Ahmet Kelesoglu Faculty of Education, Necmettin Erbakan University. Screening model was used as the research method in the present study. As data collection tools, a personal data form which was developed by researchers and by which the demographic characteristics of the study group students were obtained, and "The Digital Competence Scale" which was developed by Akkoyunlu, Yilmaz Soylu \& Caglar (2010) were used. The scale is 7 Likert type, 45 item and of four dimensions. Cronbach Alpha coefficients were calculated for the results of the scale reliability; and they were 0.86 throughout the scale, 0.94 in the first sub-dimension (Awareness), 0.84 in the second sub-dimension (Motivation), 0.78 in the third sub-dimension (Technical Access) and 0.81 in the fourth sub-dimension (Competence). The computer-aided statistical packaged program, SPSS was used in order to analyse the data collected, and the present study benefited from descriptive statistics, t-test, one-way analysis of variance and correlation methods. The study concluded that - when the digital competence of teacher candidates assessed in terms of gender in sub-dimensions of the scale - the digital competence awareness and the technical access levels of both male and female teacher candidates were high, however, their digital competence and motivation levels were close to low. Also, it has been revealed that overall average scores of teacher candidates from different branches differed significantly. Teacher candidates also differed significantly in having Internet and computers.
\end{abstract}

Keywords: digital competence level; teacher candidate; technology integration; information and communication technologies

\section{Introduction}

These rapid developments cause the communities to renew themselves and new concepts arise with this change. It is expected that individuals living in information 
communities should be those who are innovative, interrogator and productive. Almost all concepts' description is changed in the field of education today (Calik \& Sezgin, 2005). The 21 st Century is called the technology age and all communities in today's world are affected by the technological developments. Particular changes are being experienced in the light of these developments. Educational expectation is being increased because of these changes. It is now possible for the educational system to meet the expectations and progresses in the communities with the help of technology (Erkan, 2004).

The technological developments lead to particular changes in every aspect of social life. It is aimed that educational institutions raise individuals who are able to integrate technology into areas such as industry, economy and communication. Likewise, educational system expects that instructors realize this target. This target does not consist only of teaching the technology, but also using it in various aspects of life. It is necessary for the instructors who perform their profession in educational institutions and for prospective instructors receiving education in faculties of education to develop their knowledge and skills according to the ever-growing technology (Akpinar, 2003).

Digital technologies take place in the large part of our lives. The term digital technologies is used for technologies which transmit the information to a broad fraction and store it. Computers, internet, mobile devices and "Web 2.0" technologies are counted within the digital technologies (Timur, Timur \& Akkoyunlu, 2014). Optimal utilization of digital technologies means being competent numerically. Competence is the self-opinions of individuals regarding their success in certain activities (Bandura, 1986). Digital competence is the progression of skills by individuals in their lives and consolidation of their positions in the information communities by the help of digital technologies (Makinen, 2006). While providing unlimited possibilities to individuals, technological developments also lead to particular changes in the knowledge and skills of individuals which are necessary for a productive life. The ability to use digital technologies is one of these developments. It is necessary for individuals to be digitally literate at an appropriate level in order for them to correctly perceive the developments, choice of profession of other people and ever-growing world (Yildiz, Kahyaoglu \& Kaya, 2012).

Education occupies a particular place in raising manpower necessary for information community by providing the minimization of technological differences of bigger masses and the augmentation of personal skills. For this reason, it is necessary that the digital technologies are used in learning environments by students and instructors (Zhou, Burgoon, Zhang \& Nunamaker, 2004). It is essential to form the necessary sub-structure in educational institutions, to measure the digital competence levels of administrators and instructors and to determine on which variables do those levels depend in order to raise individuals who reached digital competence (Gokcearslan \& Bayir, 2011). Primarily, the acquisition of these skills by the instructors is necessary for the raising of individuals reached digital competence in educational institutions. In order to successfully complete the necessary change in educational institutions and to enhance the digital literacy skills of instructors, a life-long learning environment should be established (Akkoyunlu \& Soylu, 2010).

For this reason, the determination of digital competence levels of prospective instructors is essential since it is one of the most important components in the integration process of information and communication technologies (ICT) into education. The more prospective instructors deal with ICT tools, the more they spend time for their digital competences and the more they receive education regarding how to integrate ICT tools into their branch lessons; 
their digital competence levels will increase and ICT integration will be enhanced (Chen, 2004; Jung, 2005).

From this point of view, the goal of this study is the analysis of digital competence situations of prospective instructors in terms of different variables. Within this scope, responses of the following survey questions are sought:

(1) Do digital competence situations of prospective instructors differ in terms of their sexes?

(2) Do digital competence situations of prospective instructors differ in terms of their educational departments?

(3) Do digital competence situations of prospective instructors differ in terms of their competence levels of mobile device usage?

\section{Method}

\section{The Model of the Study and the Workgroup}

Conducted according to the screening model, this study comprises of 200 students in total; 50 students from the Department of Computer and Instructional Technologies, 50 students from the Department of Art Teaching, 50 students from the Department of Preschool Teaching and 50 students from the Department of Biology Teaching within the body of Ahmet Kelesoglu Faculty of Education, University of Necmettin Erbakan in the academic year 2014-2015 Spring.

\section{Data Collection Tools}

'Digital Competence Scale' developed by Akkoyunlu, Yilmaz Soylu \& Caglar (2010) and which is a personal information form from which demographical data of workgroup students is obtained is used as the data collection tool in this study. The scale is 7 point likert scale; 1 means 'Do not agree at all', 4 means 'Uncertain' and 7 means 'Totally agree'. This is a scale of 45 articles and four dimensions. Cronbach Alfa coefficients are calculated for the findings regarding the credibility of the scale and the following figures are found; 0.86 for the entire scale, 0.94 for the first sub-dimension (Awareness), 0.84 for the second sub-dimension (Motivation), 0.78 for the third sub-dimension (Technical Access) and 0,81 for the fourth subdimension (Competence).

\section{Data Analysis}

Data obtained in scope of the study are analyzed via SPSS (The Statistical Package for The Social Sciences) package program and all hypotheses are tested at 0.95 confidence level $(\mathrm{p}=0.05)$. Parametric tests are used during the data analysis because the data correspond to parametric test assumptions $(\mathrm{N}=200)$. Within this concept, tests used for each sub-goal are explained below.

Demographical data collected from the participants are clarified with descriptive statistical methods. T-test for unrelated samples is used in order to test whether the competence level differs reasonably according to the sexes, possession of computer and internet of the participants. Moreover, single factoral analysis of variance (Anova) for unrelated samples is 
used in order to test whether the grades obtained by the participants from the scale differs reasonably according to the weekly internet usage durations, socio-economic levels, class levels and departments, mobile device possession durations and mobile device usage efficiency situations of the participants. Furthermore, simple correlation technique is used for the determination of the relation between the general academic success and digital competence situations of the students. Correlation coefficient states two figures. First of these figures is the direction, second is the magnitude. If the correlation coefficient is 1.00 , that means there is an excellent positive relation; if it is -1.00 , that means there is an excellent negative relation. If the correlation coefficient shows 0.00 , that means there is no relation. Although there isn't a complete consensus regarding the interpretation of correlation coefficient in terms of magnitude in the literature, it may be appropriate to define the following; high relation if the correlation coefficient's absolute value is between 0.70-1.00; medium relation if it is between 0.70-0.30; and low relation if it is between $0.30-0.00$ (Buyukozturk, 2011, p. 32).

\section{Findings and Interpretations}

Table 1 demonstrates the descriptive results regarding the sexes of students in the workgroup.

Table 1. Sexes of the Workgroup

\begin{tabular}{ccc}
\hline Sex & $\mathrm{N}$ & $\%$ \\
\hline Male & 78 & 39,0 \\
Female & 122 & 61,0 \\
\hline Total & 200 & 100,0 \\
\hline
\end{tabular}

As it is clear in Table 1, among the students who participated in the study, 78 are male (39\%) and 122 are female $(61 \%)$.

Table 2 demonstrates the descriptive results regarding the distribution of students in the workgroup in terms of their educational departments.

Table 2. Distribution of Students In Terms of Their Educational Departments

\begin{tabular}{ccc}
\hline Departments & $\mathrm{N}$ & $\%$ \\
\hline CIT & 50 & 25,0 \\
Art & 50 & 25,0 \\
Biology & 50 & 25,0 \\
Preschool & 50 & 25,0 \\
\hline Total & 200 & 100,0 \\
\hline
\end{tabular}

As it is clear in Table 2, 200 students are chosen randomly as 50 each of the 4 branches.

Table 3 includes the findings concerning whether the grades which participants ontained from the digital competence scale reasonably differ or not according to the departments of students.

Table 3. Anova results of grades according to departments

\begin{tabular}{cccc}
\hline Departments & $\mathrm{N}$ & $\bar{X}$ & $\mathrm{~S}$ \\
\hline CIT & 50 & 159,72 & 24,30 \\
Art & 50 & 158,70 & 26,54 \\
Biology & 50 & 159,24 & 22,54 \\
Preschool & 50 & 155,36 & 25,80 \\
\hline
\end{tabular}




\begin{tabular}{|c|c|c|c|c|c|c|}
\hline \multicolumn{2}{|c|}{ Departments } & $\mathrm{N}$ & & \multicolumn{3}{|c|}{ S } \\
\hline \multicolumn{2}{|c|}{ CIT } & 50 & & \multicolumn{3}{|c|}{24,30} \\
\hline \multicolumn{2}{|c|}{ Art } & 50 & & \multicolumn{3}{|c|}{26,54} \\
\hline \multicolumn{2}{|c|}{ Biology } & 50 & & \multicolumn{3}{|c|}{22,54} \\
\hline \multicolumn{2}{|c|}{ Preschool } & 50 & & \multicolumn{3}{|c|}{25,80} \\
\hline \multicolumn{2}{|c|}{ Total } & 200 & & \multicolumn{3}{|c|}{24,71} \\
\hline \multirow{4}{*}{ Department } & $\begin{array}{l}\text { Variance } \\
\text { Resource }\end{array}$ & $\begin{array}{l}\text { Total of } \\
\text { Squares } \\
\end{array}$ & sd & $\begin{array}{c}\text { Average of } \\
\text { Squares }\end{array}$ & \multicolumn{2}{|l|}{$\mathrm{F}$} \\
\hline & Inter-groups & 584,775 & 3 & 194,925 & ,316 & ,814 \\
\hline & Intra-groups & 121003,220 & 196 & 617,363 & & \\
\hline & Total & 121587,995 & 199 & & & \\
\hline
\end{tabular}

As it is clear in Table 3, according to the findings obtained using the single factoral variance analysis (ANOVA) for unrelated samples, there isn't any reasonable difference among the grades of participants in terms of their departments $[\mathrm{F}(3-196)=, 316, \mathrm{p}>.05]$. In other words, the digital competence situations of the participants don't differ in terms of their departments.

Table 4 involves the findings concerning whether the grades which participants obtained from the digital competence scale reasonably differ or not according to the mobile device usage efficiency levels of students.

Table 4. Anova results of grades according to mobile device usage efficiency levels

\begin{tabular}{|c|c|c|c|c|c|c|}
\hline Rating & & & $\bar{X}$ & \multicolumn{2}{|c|}{$\mathrm{S}$} & \\
\hline \multicolumn{2}{|c|}{ Very inadequate } & & 156,0000 & \multicolumn{2}{|c|}{-} & \\
\hline \multicolumn{2}{|c|}{ Inadequate } & & 158,4286 & \multicolumn{2}{|c|}{20,21433} & \\
\hline \multicolumn{2}{|c|}{ Medium-level adequate } & & 152,5634 & \multicolumn{2}{|c|}{26,48543} & \\
\hline \multicolumn{2}{|c|}{ Adequate } & & 159,3585 & \multicolumn{2}{|c|}{22,75969} & \\
\hline \multicolumn{2}{|c|}{ Very adequate } & & 177,4667 & \multicolumn{2}{|c|}{23,40899} & \\
\hline \multirow[t]{2}{*}{ Total } & & & 158,2550 & \multicolumn{2}{|c|}{24,71831} & \\
\hline & $\begin{array}{l}\text { Variance } \\
\text { Resource }\end{array}$ & $\begin{array}{l}\text { Total of } \\
\text { Squares } \\
\end{array}$ & $\mathrm{sd}$ & $\begin{array}{l}\text { Average of } \\
\text { Squares }\end{array}$ & $\mathrm{F}$ & $\mathrm{p}$ \\
\hline \multirow{3}{*}{ Rating } & Inter-groups & 7970,705 & 4 & 1992,676 & 3,420 & 0,010 \\
\hline & Intra-groups & 113617,290 & 195 & 582,653 & & \\
\hline & Total & 121587,995 & 199 & & & \\
\hline
\end{tabular}

As it is clear in Table 4, according to the findings obtained using the single factorial variance analysis (ANOVA) for unrelated samples, there is a reasonable difference among the grades of participants in terms of their mobile device usage efficiency levels $[F(4-195)=3,420$, $\mathrm{p}<.05]$. In other words, the digital competence situations of the participants differ in terms of their mobile device usage efficiency levels.

\section{Conclusion and Suggestions}

This study aims the determination of digital competence situations of 200 prospective instructors $78(39 \%)$ of whom are male and $122(61 \%)$ of whom are female receiving education in different branches and classes in the faculty of education in terms of different variables. By result of this study, there doesn't exist any reasonable difference of digital competence situations of students in terms of their educational departments $[F(3-196)=, 316$, $\mathrm{p}>.05]$. In other words, digital competence situations of students don't differ in terms of their departments. There is a reasonable difference in terms of mobile device usage efficiency levels $[\mathrm{F}(4-195)=3,420, \mathrm{p}<.05]$. In other words, digital competence situations of participants differ in terms of mobile device usage efficiency level. 


\section{References}

Akkoyunlu, B., \& Soylu, Y. (2010). A study on teachers' digital empowerment. Turkish Librarianship, 24(4), 748-768.

Akkoyunlu, B., Soylu, M. Y., \& Caglar, M. (2010). A study on developing "Digital Empowerment Scale" for university students. Hacettepe University Journal of Education, 39(39), 10-19.

Akpinar, Y. (2003). The effect of higher education in the use of new information technologies by the teachers: the case of istanbul schools. The Turkish Online Journal of Education Technology, 2(2), 79-96.

Bandura, A. (1986). Social foundations of thought and action. Englewood Cliffs, NJ: Prentice Hall.

Chen, X. (2004). A study of stages of concern, layers of adoption, encouraging and obstructive factors about integrating information technology into instruction in junior high school language domain teachers in Kaohsiung City, Unpublished Master Degree Thesis, National Sun Yat-sen University, Kaohsiung, Taiwan.

Calik, T., \& Sezgin, F. (2005). Globalization, information society and education. Kastamonu Education Journal, 13(1), 55-66.

Erkan,S.(2004). A survey of teachers ' attitudes toward computers. Manas Journal of Social Studies, 12.

Gokcearslan, S., \& Bayir, E. A. (2011).. The investigation of student teachers' the level of digital competence. 2nd International Conference on New Trends in Education and Their Implications, 27-29 April 2011(1177-1182), Antalya, Turkey.

Goktas, Y., Yildirim, Z., \& Yildirim, S. (2008). Status of ICT in schools of teacher education: Deans' views. Education and Science, 33(149), 30-50.

Jung, I. (2005). ICT-Pedagogy integration in teacher training: application cases worldwide. Educational Technology and Society, 8(2), 94-101.

Mäkinen, M. (2006). Digital empowerment as a process for enhancing citizens' participation. E-learning and Digital Media, 3(3), 381-395.

Timur, B., Timur, S., \& Akkoyunlu, B. (2014). Determinig pre-service teachers' digital empowerment level. Mugla Sitki Kocman University Institute of Social Sciences Journal, (33), 41-59.

Yildiz, C., \& Kaya, M. K. (2012). An investigation into high school students' digital literacy level. Usak University Journal of Social Sciences, 2012(11), 82-96.

Zhou, L., Burgoon, J. K., Zhang, D., \& Nunamaker, J. F. (2004). Language dominance in inter personal deception via computer-mediated communication. Computers in Human Behavior, 20(3), 381-402. 